\title{
Correction to: Emerging role of lipid metabolism alterations in Cancer stem cells
}

Mei $\mathrm{Yi}^{1,2}$, Junjun $\mathrm{Li}^{1,3}$, Shengnan Chen ${ }^{1,3}$, Jing Cai ${ }^{1,3}$, Yuanyuan Ban ${ }^{1,3}$, Qian Peng ${ }^{1,3}$, Ying Zhou ${ }^{1,3}$, Zhaoyang Zeng ${ }^{1,3}$, Shuping Peng ${ }^{1,3}$, Xiaoling Li ${ }^{1,3}$, Wei Xiong ${ }^{1,3}$, Guiyuan Li, $i^{1,3}$ and Bo Xiang ${ }^{1,3^{*}}$

\section{Correction}

In the publication of this article [1], there is an error in the Figure caption of Figs. 2, 3 and 4. This has now been included in this correction. The authors declare that these corrections do not change the results or conclusions of this paper.

The error: In the initially published version of this article, the caption for Figs. 2, 3 and 4 were incorrectly presented due to a mistake.

The correct captions for Figs. 2, 3 and 4 are given hereafter:

\section{Author details}

${ }^{1}$ Hunan Provincial Cancer Hospital and Cancer Hospital Affiliated to Xiangya Medical School, The Central South University, Changsha 410013, Hunan, China. ${ }^{2}$ Department of Dermatology, Xiangya hospital of Central South University, Changsha 410008, China. ${ }^{3}$ Cancer Research Institute, Xiangya School of Medicine, Central South University, Changsha 410078, China.

Received: 23 June 2018 Accepted: 23 June 2018

Published online: 16 July 2018

\section{Reference}

1. Yi M, Li J, Chen S, et al. Emerging role of lipid metabolism alterations in Cancer stem cells. J Exp Clin Cancer Res. 2018;37(1):118. https://doi.org/10. 1186/s13046-018-0784-5.

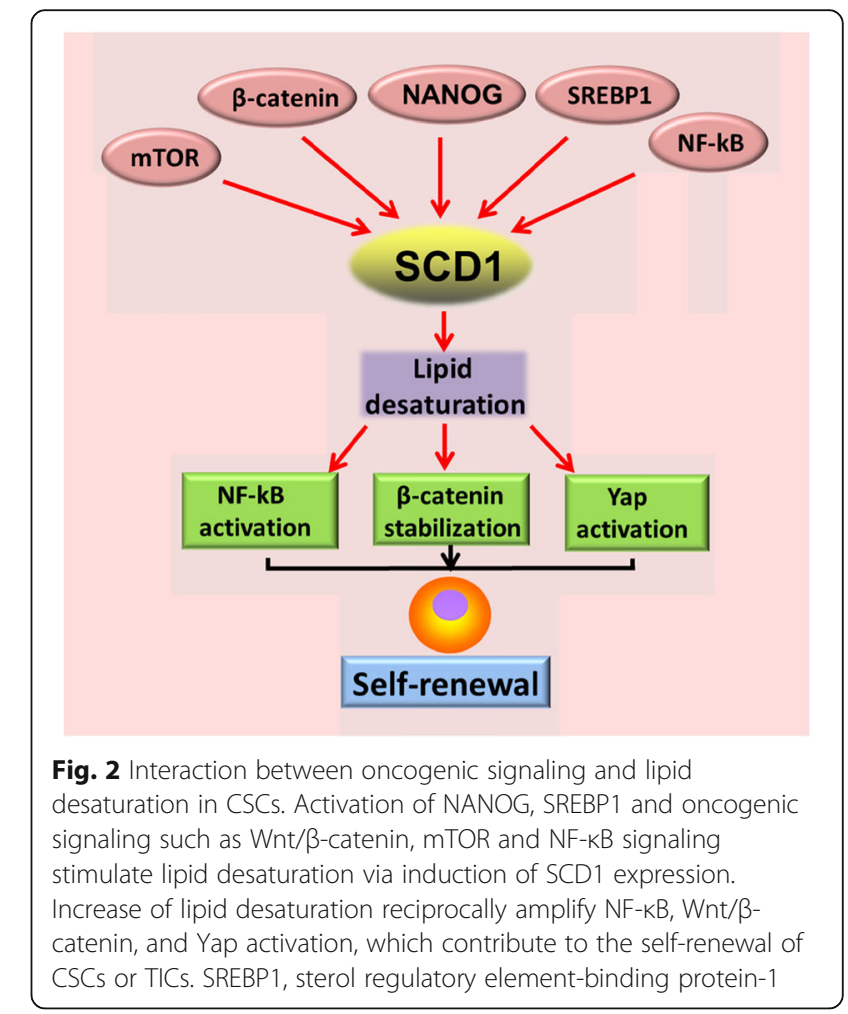

\footnotetext{
*Correspondence: xiangbolin@csu.edu.cn

${ }^{1}$ Hunan Provincial Cancer Hospital and Cancer Hospital Affiliated to Xiangya Medical School, The Central South University, Changsha 410013, Hunan, China ${ }^{3}$ Cancer Research Institute, Xiangya School of Medicine, Central South University, Changsha 410078, China

Full list of author information is available at the end of the article
}

(c) The Author(s). 2018 Open Access This article is distributed under the terms of the Creative Commons Attribution 4.0 International License (http://creativecommons.org/licenses/by/4.0/), which permits unrestricted use, distribution, and reproduction in any medium, provided you give appropriate credit to the original author(s) and the source, provide a link to the Creative Commons license, and indicate if changes were made. The Creative Commons Public Domain Dedication waiver (http://creativecommons.org/publicdomain/zero/1.0/) applies to the data made available in this article, unless otherwise stated. 


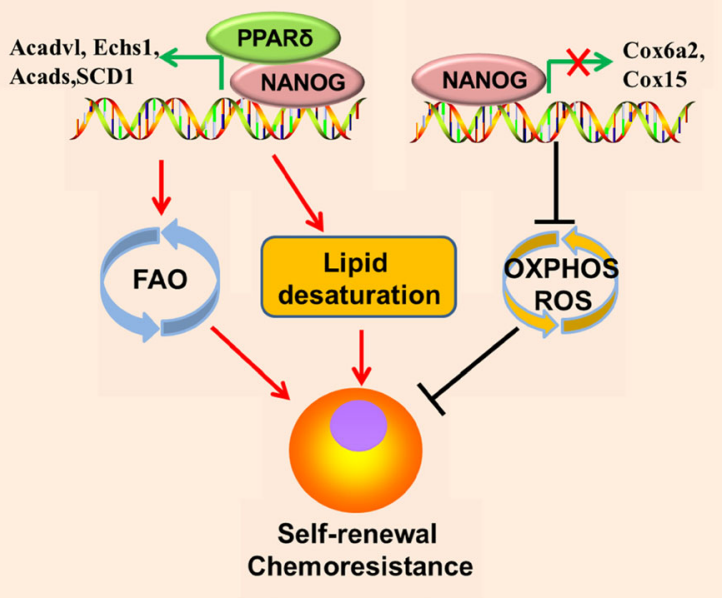

Fig. 3 NANOG mediated metabolic reprogramming contributes to CSCs self-renewal and chemoresistance. NANOG binding on FAO genes (Acadvl, Echs1, and Acads) promoters stimulates it's transcription but exerts opposite effect on OXPHOS genes(Cox6a2 and Cox 15) transcription, leading to metabolic switch from OXPHOS to FAO and less ROS production in CSCs/TICs. NANOG also promotes lipid desaturation via up-regulating SCD1 expression. OXPHOS, oxidative phosphorylation; FAO, fatty acid oxidation

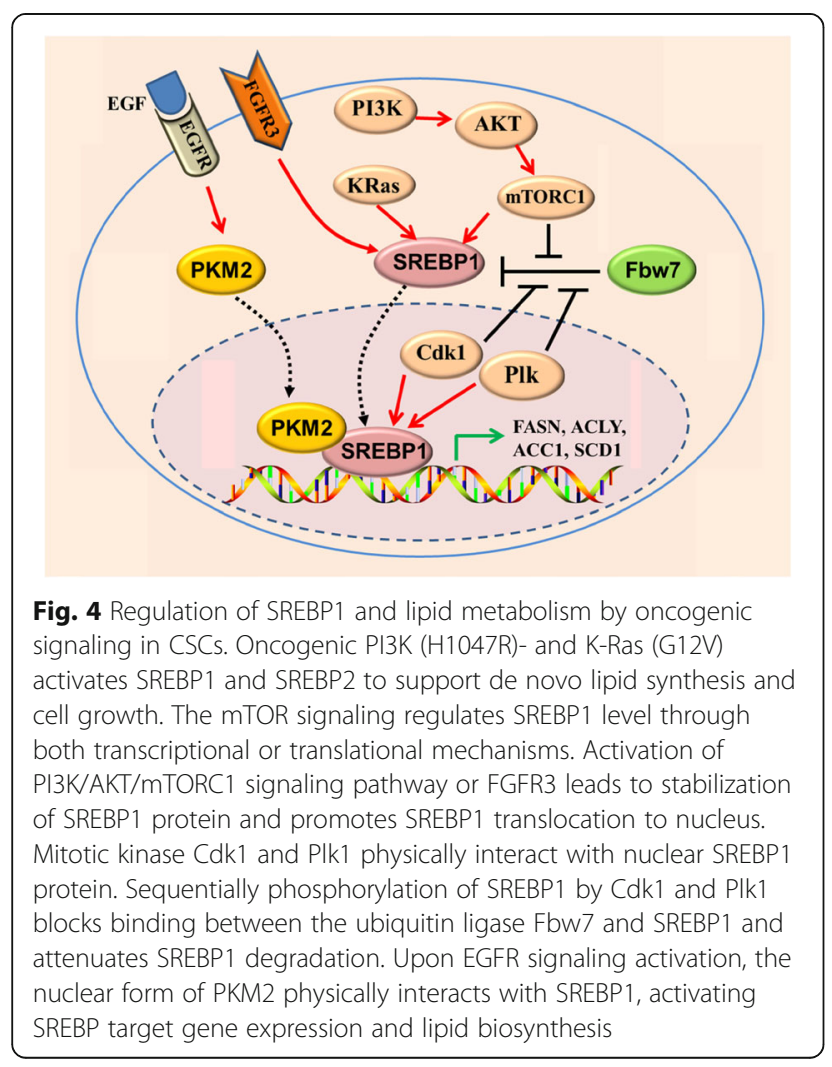

